\title{
Induction of the Petite Mutation in Saccharomyces cerevisiae by $N$-Methyl- $N^{\prime}-N i t r o-N$-Nitrosoguanidine
}

\author{
By K. NORDSTRÖM* \\ Division of Applied Microbiology, The Royal Institute of Technology, \\ Stockholm 70, Sweden
}

(Accepted for publication I5 March 1967)

\begin{abstract}
SUMMARY
$N$-Methyl- $N^{\prime}$-nitro- $N$-nitrosoguanidine (NTG), which is known to be a very effective mutagen in many systems, induces petite mutations when cells of Saccharomyces cerevisiae are treated in acetate buffer. Fifty per cent or more of the survivors may be petite mutants. NTG is a real mutagen in the process since the number of mutants increases at short times of exposure to NTG although the total number of cells decreases. Growing cells are more susceptible to killing and mutation than are cells in buffer. The production of petites may cause difficulties when screening for rare auxotrophs.
\end{abstract}

\section{INTRODUCTION}

$N$-methyl- $N^{\prime}$-nitro- $N$-nitrosoguanidine (NTG) is highly cancerostatic in mammalian systems (Greene \& Greenberg, 1960) and highly mutagenic in microbial cells (Adelberg, Mandel \& Chen, 1965). It has been reported that NTG-resistant mutants of Escherichia coli are induced with high frequency by exposure to NTG (Mandell \& Greenberg, 1960); the process was shown to be due to de novo mutations and not to the selection of preformed mutants. NTG is also an excellent agent for the induction of auxotrophs in bacteria (Adelberg et al. 1965) and in yeast (Megnet, 1965).

Auxotrophs with respect to a defined biosynthetic pathway are formed in rather low frequencies by various mutagenic treatments. Thus, successful isolation of them often requires the use of selection or screening. A number of selection methods have been adopted since Lederberg \& Zinder (1948) and Davis (1948) introduced the penicillin method for selective killing of bacterial prototrophs in mixture with auxotrophs.

Several methods for the selection of yeast auxotrophs have been investigated. Megnet has successfully used inositol deficiency (1964) or 2-deoxyglucose (I965) as selective agents for Schizosaccharomyces pombe auxotrophs. Moat, Peters \& Srb (1959) tried several antibiotics for the selection of Saccharomyces cerevisiae auxotrophs. It was found, however, that the recognition of the mutants after replica plating or delayed enrichment was obscured by the simultaneous induction of respiratory deficient mutants, the so-called petites. These grow more slowly aerobically than the wild type and may, thus, present a negative result on minimal medium if the plates are studied after a short incubation period. However, it is possible to identify petites by various methods; they remain white when the wild type is coloured red by an overlay of triphenyl tetrazolium chloride (TTC) agar (Nagai, 1959; Nagai, Yanagishima \& Nagai, I96I; Ogur, St John \& Nagai, I957).

* Present address: Department of Microbiology, University of Umeå, Umeå, Sweden. 
Petites are induced by a great number of agents, the most notable being acriflavine (Nagai et al. 196I), The site of the mutation is extranuclear; it seems to be located within the mitochondria (Ephrussi, 1953). The latter have recently been shown to contain DNA (Schatz, Halsbrunner \& Tuppy, 1964), which may explain their relative autonomy with respect to the nucleus. At higher concentrations of acriflavine, up to I00\% of the population is transformed to petites. Ephrussi (1953) has shown that petites do not arise by selection of pre-existing mutants but are induced de novo in all cells.

The aim of the present work was to find methods for the selection of auxotrophs of yeast, especially of Saccharomyces. Since NTG is such a good mutagenic agent in many organisms, even in the yeast species Schizosaccharomyces (Megnet, I965), it was used to induce mutations. It was then necessary to study whether petite mutations were induced by NTG. This part of the work is reported in this paper.

\section{METHODS}

A strain of Saccharomyces cerevisiae, isolated from commercial baker's yeast, was used. It was grown without aeration in $100 \mathrm{ml}$. of $9 \%(\mathrm{w} / \mathrm{v})$ unhopped beer wort in $200 \mathrm{ml}$. Erlenmeyer flasks at $25^{\circ}$. All platings were made on wort agar $(2 \%(\mathrm{w} / \mathrm{v})$ agar $)$.

Actively growing cells were centrifuged and washed twice with $0.9 \%(\mathrm{w} / \mathrm{v})$ saline and suspended in $0.2 \mathrm{M}$-acetate buffer $\left(\mathrm{pH} 5^{\circ} 0\right.$ ) (Megnet, 1965) to a concentration of $2 \times 10^{7}$ cells $/ \mathrm{ml}$. NTG was dissolved without sterilization in the same buffer immediately before the mutation experiments (Adelberg et al. 1965). One ml. of yeast suspension and $2 \mathrm{ml}$. of NTG solution were mixed (Megnet, I965) and incubated at $25^{\circ}$. Samples were diluted from time to time in saline and $0.1 \mathrm{ml}$. was plated on wort agar. If the NTG concentration of the solution to be spread was $0.1 \mathrm{mg}$. $/ \mathrm{ml}$. or more $0 \cdot 1 \mathrm{ml}$. was diluted in saline and filtered through a millipore filter. The filter was then placed on wort agar. Without this filtration, a considerable portion of the cells plated were killed on the plates (cf. Fig. I).

In another series of experiments, yeast was exposed to NTG in a medium permitting growth, namely wort. Io ml. medium was incubated in $25 \mathrm{ml}$. test tubes. After various times of incubation, aliquots were diluted in saline and spread on wort agar.

The plates were incubated at $25^{\circ}$. Colonies could be detected after 2 days, but petite colonies require a longer incubation period. After 5 days, the colonies in each Petri dish were overlayed (Nagai, 1959; Nagai et al. 1961; Ogur et al. 1957) with $20 \mathrm{ml}$. melted agar $(\mathrm{I} \cdot 5 \%(\mathrm{w} / \mathrm{v}))+$ phosphate buffer $(0.067 \mathrm{M}, \mathrm{pH} 7 \cdot 0)$, glucose $(5 \mathrm{~g} . / 1$.$) , and$ TTC (I g./1.); the solution was melted and then kept at $45^{\circ}$. TTC was added immediately before the solution was poured on to the colonies since TTC is not very stable (Ogur et al. 1957). White and red colonies were counted after $3 \mathrm{hr}$, but the plates could even be scored the next day.

For comparison, acriflavine was added to growing yeast cells in $10 \mathrm{ml}$. wort in $25 \mathrm{ml}$. test tubes. Samples were diluted and spread after various times of incubation at $25^{\circ}$ and treated in the same way as the NTG samples with TTC overlay.

To show the killing effect of NTG on the plates, the following experiment was performed. $0.1 \mathrm{ml}$. cell suspensions was spread on wort agar. When the plates were dry, $0.1 \mathrm{ml}$. NTG solutions of various concentrations was added. The plates were incubated and the colonies counted after TTC overlaying as described above. 


\section{RESULTS AND DISCUSSION}

Killing on the plates. The lethal effect of NTG on cells plated on wort agar is shown in Fig. I. It can be seen that the NTG concentration in the added solution may reach $0 \cdot \mathrm{I} \mathrm{mg} . / \mathrm{ml}$. without any appreciable lethal effect. At higher concentrations, however, the number of detectable colonies decreases considerably. Thus, it was necessary to dispose of NTG when the samples were not diluted to a concentration below 0.1 $\mathrm{mg}$. $/ \mathrm{ml}$. Indeed, NTG incorporated in the plating agar has been used to induce revertants in situ (Marquardt, Zimmermann \& Schwaier, 1964).

Adelberg et al. (1965) recommend a mutation procedure in which the cells are collected on millipore filters and NTG is washed away with buffer. This procedure is not necessary in yeast if the concentration of NTG is low in the solution plated, since

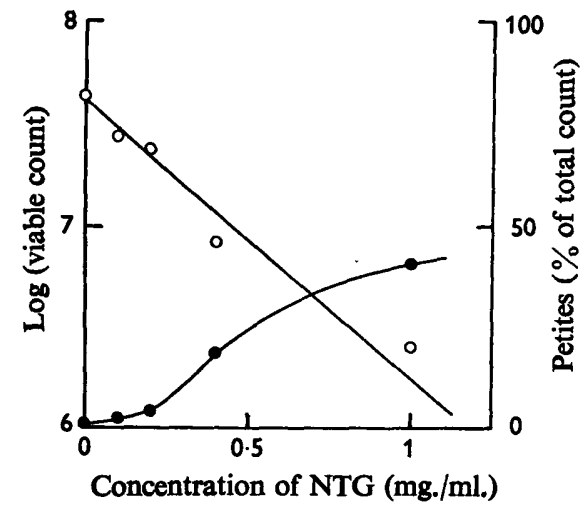

Fig. I

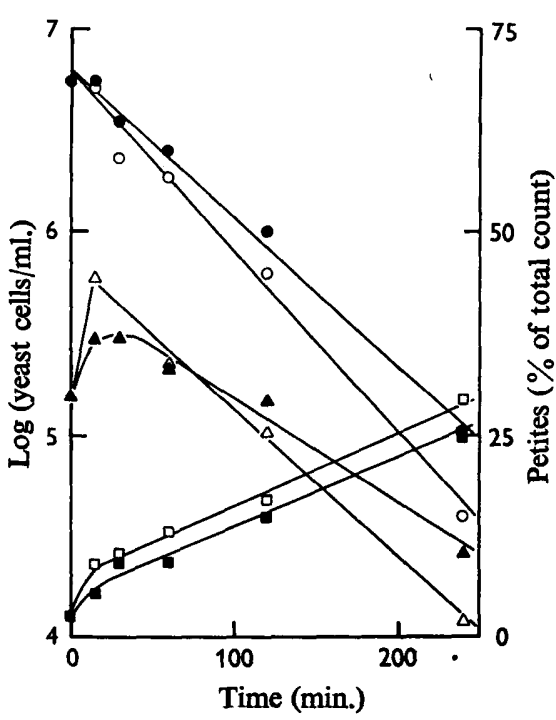

Fig. 2

Fig. I. $0.1 \mathrm{ml}$. of yeast suspension was spread on wort agar and allowed to dry, then 0.1 $\mathrm{ml}$. NTG solutions (concentration given on theabscissa) was spread on the agar surface. Viable count $(O)$ and petite fraction $(O)$ were determined.

Fig. 2. Effect of NTG treatment on viable count (circles), petite count (triangles), and petite fraction (squares). The yeast was treated with $2 \cdot 0$ (open symbols) or $1 \cdot 0$ (closed symbols) $\mathrm{mg} . / \mathrm{ml}$. NTG in acetate buffer during the time indicated on the abscissa.

Table I. Effect of NTG on viable count

The values have been taken from Figs. 2 and 3 and from additional experiments.

$\begin{array}{ccc}\text { NTG concentration } \begin{array}{c}\text { Time required to reduce the viable } \\ \text { (mg./ml.) }\end{array} & \text { In buffer } & \text { In wort } \\ 2.0 & 110 & 40 \\ 1.0 & 140 & - \\ 0.4 & 170 & - \\ 0.2 & 210 & -\end{array}$


petites were induced to only a small extent at concentrations below $0.2 \mathrm{mg} . / \mathrm{ml}$. (Fig. I).

Death curves of NTG-treated cells. The plate counts decreased with time when cells were suspended in NTG solutions (Fig. 2). Time zero means that the samples were diluted and plated immediately after the addition of NTG. Linear curves were obtained for $\log N_{t} / N_{0}$, where $N_{t}$ and $N_{0}$ are the viable counts at time $t$ and zero, respectively. At $2 \mathrm{mg}$. $/ \mathrm{ml}$. the viable count decreased by a factor of Io every I IO min. The slopes of the survival curves obtained with various concentrations of NTG are given in Table I. Still steeper slopes were obtained when cells were exposed to NTG in wort; the viable count decreased by a factor of 10 within $40 \mathrm{~min}$. at a NTG concentration of $2 \mathrm{mg}$. $/ \mathrm{ml}$. (Fig. 3). An increased lethal effect in media permitting growth has been

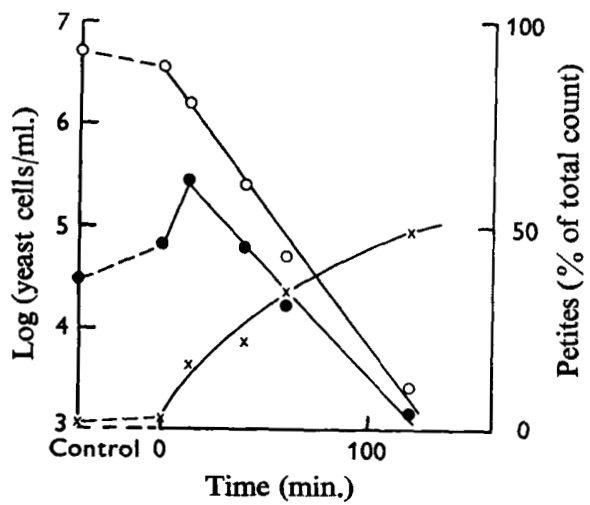

Fig. 3

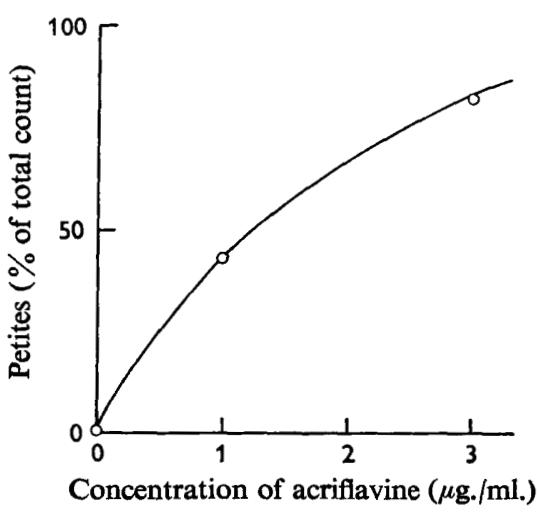

Fig. 4

Fig. 3. Effect of NTG treatment on viable count (O), petite count ( $\bullet$ ), and petite fraction $(x)$. The yeast was treated with $2.0 \mathrm{mg} . / \mathrm{ml}$. NTG in wort during the time indicated on the abscissa.

Fig. 4. Effect of acriflavine treatment on petite fraction. The yeast was incubated for $48 \mathrm{hr}$ in wort to which acriflavine was added. The wort was inoculated with $8 \times 10^{6} \mathrm{cells} / \mathrm{ml}$., which was about $1 / 10$ of the final count obtained.

obtained by Adelberg et al. (1965) in experiments with Escherichia coli. These authors also report that the fraction of mutants among the survivors was the same when cells were treated in buffer and in growth-promoting media. They thus recommend a procedure in which the mutagenic treatment is performed in buffer. They also report that $40 \%$ of the survivors of $E$. coli were auxotrophs when treated with $\mathrm{r}$ mg. NTG/ $\mathrm{ml}$. Megnet (I965) used $2 \mathrm{mg}$. NTG/ml. to induce auxotrophs in Schizosaccharomyces pombe; he found $8 \%$ auxotrophs without screening. If, however, a particular kind of auxotroph is required, the probability of finding it is much less than these figures may indicate. The figures are a measure of the induction of a great number of mutants with many kinds of deficiencies. Adelberg et al. (1965) assume that about 10 \% of the total genome consists of loci capable of mutations giving rise to autotrophs. Screening procedures may be needed if more specified auxotrophs have to be isolated.

Induction of petites. The induction of petites in non-growing and in growing cells is illustrated in Figs 2 and 3. In the controls, the petite fraction was $0.7 \%$. The absolute number of petites increased by NTG treatment and a great number of the sur- 
vivors were mutants. This result is comparable to the effects of acriflavine on growing cells (Fig. 4), where the majority of the cells are mutants. Several $\mu \mathrm{g} . / \mathrm{ml}$. of acriflavine can be included in the medium without significant effects on the growth rate (Ephrussi, 1953).

The results of this paper show that a great portion of the survivors after NTG treatment consists of petite mutants. This may create some difficulty in the isolation of auxotrophs of Saccharomyces. Studies on the selection of auxotrophs of yeast are in progress in this laboratory.

This work was supported by the Swedish Technical Research Council. The skilful technical assistance of Mrs Kerstin Ekengren-Jansson is gratefully acknowledged.

\section{REFERENCES}

Adelberg, E. A., Mander, M. \& Chen, G. C. C. (1965). Optimal conditions for mutagenesis by $N$-methyl- $N^{\prime}$-nitro- $N$-nitrosoguanidine in Escherichia coli $\mathbf{x} 12$. Biochem. biophys. Res. Commun. I8, 788.

Davis, B. D. (1948). Isolation of biochemically deficient mutants of bacteria by penicillin. J. Am. chem. Soc. 70, 4267.

EPHRUSSI, B. (1953). Nucleo-Cytoplasmic Relations in Microorganisms. Their Bearing on Cell Heredity and Differentiation, p. 13. London: Oxford University Press.

GreENE, M. O. \& GREENBERG, J. (1960). The activity of nitrosoguanidines against ascites tumors in mice. Cancer Res. 20, 1166.

LEDERBERG, J. \& ZINDER, N. (1948). Concentration of biochemical mutants of bacteria with penicillin. J. Am. chem. Soc. 70, 4267.

MANDeld, J. D. \& GreenberG, J. (1960). A new chemical for bacteria, I-methyl-3-nitro-I-nitrosoguanidine. Biochem. biophys. Res. Commun. 3, 575.

Marquardt, H., ZimmermanN, F. \& SchwaIeR, R. (1964). Die Wirkung krebsauslösender Nitrosamine und Nitrosamide auf das Adenin-6-45-Rückmutatationssystem von Saccharomyces cerevisiae. $Z$. Vererbungslehre $95,82$.

Megnet, R. (1964). A method for the selection of auxotrophic mutants of the yeast Schizosaccharomyces pombe. Experientia 20, 320.

MEGNET, R. (1965). Screening of auxotrophic mutants of Schizosaccharomyces pombe with 2deoxyglucose. Mutation Res. 2, 328.

Moat, A. G., Peters, Jun., N. \& Srb, A. M. (1959). Selection and isolation of auxotrophic yeast mutants with the aid of antibiotics. J. Bact. 77, 673.

NAGAI, S. (1959). Induction of the respiration-deficient mutation in yeast by various synthetic dyes. Science 130, 1188.

NAGAI, S., YANAGISHIMA, N. \& NAGAI, H. (I96I). Advances in the study of respiration-deficient (RD) mutation in yeast and other microorganisms. Bact. Revs. 25, 404.

OGUR, M., ST John, R. \& NAGAI, S. (1957). Tetrazolium overlay technique for population studies of respiration deficiency in yeast. Science $125,988$.

Schatz, G., Halsbrunner, E. \& TuPPy, H. (I964). Deoxyribonucleic acid associated with yeast mitochondria. Biochem. biophys. Res. Commun. $15,127$. 